\section{Reactivity of Freshly Formed Steel Surfaces}

PrINoe ${ }^{1}$ has observed that a freshly sheared steel surface rusts far quicker than would be expected at ordinary temperatures. Whether or not it is always legitimate, in statistically distributed events, to draw conclusions from isolated observations, recorded facts support his statement in the present case. The corrosion probability of a freshly scraped surface is higher than that of a surface exposed to air; statistical studies by Mears ${ }^{2}$ have shown that the probability number for rusting at scratch lines traced on iron, and, after exposure to air, covered with $0.07 M$ sodium bicarbonate, declines steadily with the duration of exposure.

Prince tentatively suggests that hydrogen peroxide plays a part in the rusting, apparently by converting ferrous to ferric hydroxide; under ordinary conditions, however, ferrous hydroxide would be oxidized by atmospheric oxygen, and there is no need to postulate hydrogen peroxide as the oxidizing agent. Incidentally, Pietsch and his colleagues ${ }^{2}$ showed that the addition of pure (unstabilized) hydrogen peroxide to water prevented or postponed the rusting of homogeneous iron, which occurred rather quickly in water free from peroxide ; possibly this passivation might not occur on steel--nor with hydrogen peroxide as found in the reagent bottle.

19 Manor Court, Grange Road, Cambridge.

- Prince, A., Nature, 176, 223 (1955).

- Mears, R. B., and Evans, U. R., Trans. Farad. Soc., 31, 527 (1935) ${ }^{3}$ Pietsch, E., Grosse-Eggebrecht, B., and Roman, W., Z. phys. Chem., A, 157, 363 (1931).

\section{An Epidemic of Words}

EPIDEMiology is a fascinating subject. Much the same interest is aroused and the same scientific principles involved whether, with Lodge in 1603, we discuss an "epidemick [of plague] . . . common unto all people or most of them" ; or with Morgan in 1728 we discover that the mange is the "epidemical distemper" of the camels of the Algerians; or we realize with Berkeley (1857) that it was an epidemic of Irish blight which sent the Irish to New York and Now Holland during the 'forties of the last century; or (more metaphorically as we nowadays think) we may disagree with John Milton (1643) that divorce is a "toleration of epidemick whordom". Thus 'epidemic', soon after the word was coined, came to have a wider and a narrower meaning than the original Greek $\varepsilon \pi \iota \delta \eta \mu o s$. Epidemiology has apparently retained this wide meaning. It is correct to discuss the epidemiology of myxomatosis in the rabbit, and when we discuss the epidemiology of Irish blight we know we are not discussing a direct attack of Phytophthora infestans on the unfortunate Irish, although perhaps there may have been an indirect attack on them by way of the potato murrain.

Epidemics are, of course, dangerous things. Although I could see no scientific reason for the recent re-introduction and popularization of the word 'epizootic' to discuss myxomatosis, there may have been some political reasons. I now find that $I$ have been in error in referring to an epidernic of Irish blight, Hayos and Immer in 1942 referring to the artificial production of epiphytotics on plants. In future, epidemics on plants should be referred to, not as epiphytics (Lindley in 1830 having defined this word correctly and according to the original
Greek), but as 'epiphytotics', to rhyme, one supposes, with epizootics, which, of course, except for Todd's pre-emption in 1836, might have been epizoics.

This is a small epidemic of words. Epidemics are infectious diseases. Unless strong antiseptics are used, we may soon find ourselves with a new science of epibiology (or should it be epibioticology ?), with the three subsciences of epidenaiology, epizoology (or epizooticology ?) and epiphytology (or epiphytoticology ?).

The related word 'endemic' has travelled a long way in meaning since Stanley's description in $\mathbf{1 6 5 7}$ of "Those endemical malignant vapours, which infect the air". Its modern scientific use was carefully defined by Charles Darwin in the first edition of "On the Origin of Species" (1859), when he wrote "in oceanic islands..., the proportion of endemic species (i.e. those found nowhere else in the world) is often extremely large". Cannot our epidemiologists define an epidemic to include epidemies on populations of all living organisms, whether man, potato, rabbit or bacterium?

Since writing the above, I have found that the epidemic of words has already started, Large, in 1940, referring to the new American science of 'epiphytotiology' or the use of meteorology in the prediction of epidemics on plants. University of Tasmania.
July 6.

H. N. Barber

\section{"Educational Problems of the Colonial Territories"}

IN the leading article in Nature of August 20 on "Educational Problems of the Colonial Territories", it is stated that "only some 450 scientists are at present engaged in Colonial research", and that "any expansion in research must draw largely on the limited supplies of scientific and technical man-power in Britain itself". Most British scientific workers are superannuated at the age of approximately sixty-five. Many of them are capable of another ten years of research, and a moderate amount of teaching. Some, at loast, would be happy to work in a Colonial university or research institute. The necessary qualifications are the capacities to work in a tropical or subtropical climate, and to form friendships with non-Europeans.

Many branches of biology and geology, not to mention mathematics, require little expensive apparatus; and a salary less than that of a junior lecturer would be a welcome supplement to a pension. The research carried out would not often be of immediate economic applicability, but it would, I think, be of cultural value.

I may have over-estimated the number of suitably qualified British scientists available, but I think that the presence in a Colonial university of even two or three Fellows of the Royal Society carrying out fundamental research with African or Asian colleagues would help the local population to generate its own scientific culture.

Until it has been proved that elderly British scientists will not accept such offers, I doubt whether those interested in the intellectual development of the Colonies are justified in complaining of lack of man-power.

Department of Biometry,

J. B. S. HATDANE

University College, London, W.C.I. 